\title{
WENELA
}

\section{PHYSIOTHERAPY and REHABILITATION CENTRE}

This Centre is part of the Wenela Hospital in Johannesburg. It is situatcd about one mile from the centre of the city on its southern side near Booysens Railway Station

The hospital complex consists of the new section and the older part. It comprises 37 wards -- surgical, medical, eye, spinal isolation and pneumoconiosis medical bureaux, operating theatres, recovery room and special carc unit, X-ray departments and administrative offices.

This hospital is connected with the South African Chamber of Mincs. It serves as the major central hospital on the east, central and west Rand and other places in the Transvaal, Orange Free Stale and Northern Natal. lis medical stafl is composed of the Chief Medical Officer and ten olher medical officers. It also has at its disposal orthopaedic surgeons. neurosurgeons, E.N.T. surgeons, ophthalmic surgeons. thoracic surgeons, general surgeons, radiologists and physicians. Physiotherapists, radiographers, medical technologists and adequate nursing staff represent paramedical and nursing services

\section{TYPES OF PATIENTS IREATED}

The patients treated in this hospital are male in-patients employed in the mining industry. Most of these patients are referred to this hospital from their local mine hospitals by their own Senior Medical Officers. A patient may be referred for one of the following:-

Specialists' attention, opinion, treatment, physiotherapy or a combination of I wo or more of these.

In their majority the patients are traumatic cases injured at work or outside work. These patients are:-

(i) Upper and lower limb fractures

(ii) Brachial Plexus lesions.

(iii) Other Peripheral nerve injuries (mostly upper limb).

(iv) Re-education after tendon transfers; and

(v) Many recent injuries of major extenl.

(vi) We also receive paraplegics and quadriplegics, hemiplegics due to head injuries and a fair number of medical and surgical conditions.

Our patients are tribesmen from Angola, Botswana, Malawi, Swaziland, Portuguese East Africa, Lesotho, Transkei and various parts of the Republic. With so many difierent tribesmen with different traditions, cultures, customs and creeds we ought to have difficulties in language and direct communication. However, the mines have developed their own communication language called FANAKALO which is easy 10 understand and speak.

\section{STAFFING OF THE REHABILITATION CENTRE}

There are four physiotherapists in this hospital: $\mathbf{M r}$. A. Rothberg (Superintendent Physiotherapist), Miss A. Gammon (M.C.S.P.), Mr. B. B. Ngcobo (National Diploma) and myself. Mr. A. Rothberg, who started the Rehabilitation Centre in this hospital in 1946, has orderlies trained in the department. These orderlies help us in preparing the patients before treatment and clear up after the treatments. The orderlies lurther help us when walking the patient with crutches. The physiotherapist stands in front of the patient giving orders and direclion while an orderly is behind the patient for support to prevent the patient falling backwards. The orderlies also act as porters, transporting the spinal cases from and to the Centre.

All the orderlies are male except one lady who is employed as crafts instructress. She attends mainly to the arm and hand injuries by showing them knitting, painting, beadwork, modelling, etc.
B. D. MASHEGO

Physiotherapist (National Diploma)

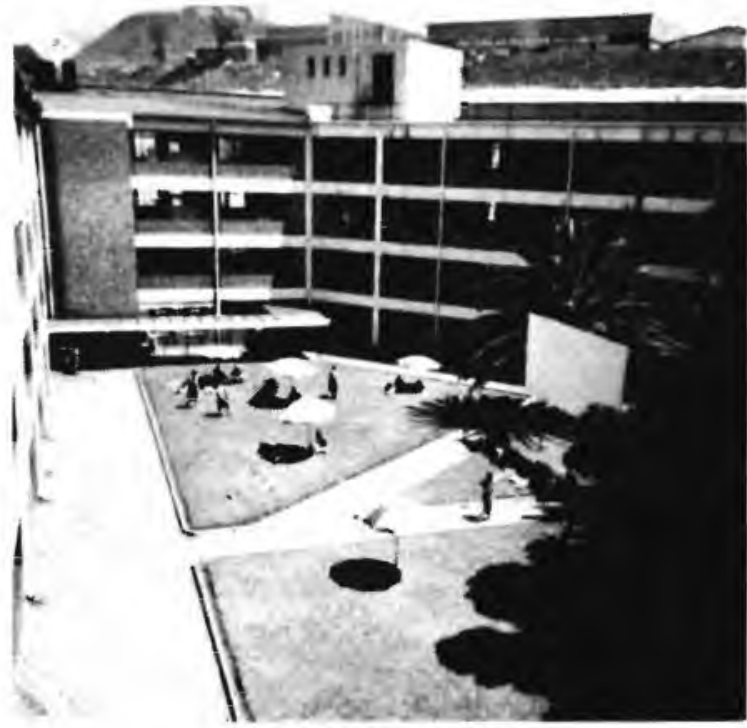

Part of Wenela Hospital.

The Specialist in Physical Medicine, Dr. C. Adler, holds a weekly review and discharge clinic and a clinic for assessment of spinal cases.

\section{EQUIPMENT IN THE PHYSIOTHERAPY DEPARTMENT}

Our physiotherapy department is equipped with the usual physiotherapeutic machines such as Faradic and Faradic Galvanic and other muscle stimulators, short-wave diathermy, infra-red lamps. Kromayer and mercury vapour ultra-violet lamps, ultra-sound and wax baths. For strengthening movements we have weights and pulley systems, springs, suspension units, special boots and sand bags. Further, we have plinths, beds with wooden crossbars on Iop so arranged that we can use them for suspension therapy. These types of beds are still kept in use to be shown to the students who come here for their lectures so that if it happens that after completion of their studies they are employed in an outside hospital where Guthrie Smith suspension frames are not easily obtainable, they can improvise such beds which serve almost the same purpose. We have a stationary bicycle and two bed cycle exerciser so that the patient can cycle while lying on the bed. These are used for mobilisation and strengthening movements in lower limb injuries. Wall bars, parallel bars, back entension exerciser, tilting tables for postural drainage and for standing the patient up for the first time and walking aids.

For the rehabilitation of the spinal cases we have the lilling lable used as above; walking machines, crulches, calipers and boots, wheel chairs, stable beds, stairs, stable standing apparatus in which the patient can be fixed with belts and play table tennis, throw javelin, discus and shol-put. Playing in the erect position helps ihe patient to practise balance and strengthen the abdominal wall muscles and finally gives the patient a chance to see himself in the standing position and competing with normal persons. 
For encouragement of deep breathing we have a table where chest patients sit around and "play football" by blowing table tennis balls into small goals. Finally we have a radio and a radiogram, which are very useful for class and group exercises.

\section{SUPPLY OF APPLIANCES}

(i) Spinal Cases: Before discharge a completely paraplegic patient is issued with a wheelchair complete with four-inch-thick foam blocks; one pair of aluminium elbow crutches, a pair of calipers complete with boots. The patient may be issued with a spinal brace depending on the stability of the fracture site. In incomplete lesions, e.g. lesions of the cauda equina, where a patient suffers a mono- or bilateral foot drop, he is issued with two sticks and boots with below knee calipers and toe-raisers.

(ii) Lower Limb Fractures: A patient with severe fractures of the pelvis is usually supplied with a pair of elbow crutches and boots. One of the boots may be raised if one leg is shorter than the other.

A patient with fractures of ibia or tibia and fibula and a patient who has suffered foot injuries walks often much better when he has the benefit of boots with heels. It has, therefore, become routine to supply boots and one stick (if necessary) to these patients.

Patients with fractured femur rarely need walking aids on discharge. If necessary, they are supplied with crutches or sticks and boots. It must be borne in mind that these patients return to work and not to a convalescent home. If the patient is seriously injured or handicapped, he is then repatriated after being compensated.

In complicated lower limb fractures where the anterior tibial nerve is involved, the patient is issued with boots, one with a toe-raiser. A stick may be supplied if necessary.

(iii) Due to a higher rate of successful upper limb tendon transplants and intensive, successful rehabilitation in this hospital, upper limb splints are worn very temporarily prior to operation. Since I have arrived in this hospital, in September, 1970, I have never seen a patient discharged home with an upper limb splint.

Amputees: A patient with above or below knee amputation is supplied with the appropriate prosthesis and usually only one stick. But, due to physiotherapy which the patient receives, especially if he is referred to us as early as possible, the below knee amputees rarely need a stick.

A patient with upper limb amputation is supplied with an arm prosthesis and fully trained how to use it before he is discharged home.

\section{SOME IMPROVISATIONS}

Apart from a Guthrie Smith suspension frame, we have seven stabilised beds with adjustable, wooden cross-bars. on top so that we are able to carry out suspension therapy and resistances with springs almost from any angle as mentioned before.

For the hand we have pieces of hose pipes, sponges taken from axillary crutch paddings with which the patient can practise grip before trying the strong hand springs, apart from the conventional dumbells, etc.

If the patient needs a temporary cock-up splint, we sometimes improvise with flexible cramer wire padded and reinforced with a bandage.

If a patient's leg is in plaster of paris and he is to start with partial weight bearing. on the affected leg, instead of the surgical heel, one can fix a rubber heel with leather straps and the patient walks with this.
If the patient has a sore on the back of the heel and cannot wear his boots due to this, we sometimes use an old boot, cut the back part of the "uppers" off and make a home-made sandal out of it.

\section{THINGS I HAVE LEARNED SINCE QUALIFYING}

(i) Some surgeons allow a patient who has had meniscectomy to take weight as early as possible, even within 24 hours after the operation without causing any side effects. For knee mobilisation, however, we wait until the stitches are taken out.

(ii) If equipment is well looked after, it lasts a long time. To make this point to the students, some of the machines in the department are over 20 years old, yet are still working well.

(iii) There can be full co-operation between physiotherapists and the nursing staff and between the physiotherapists and the patients. The patients here are very eager to come to the "school" as they want to "pass" and go home or back to work.

(iv) With proper nursing care and rehabilitation, our paraplegic patients are ready for discharge between four and six months. Complete paraplegics, with a lesion at the anatomical level of T12/Ll or lower we expect to be walking with calipers and elbow crutches within four months from the accident.

(v) There is a "self-propulsion trolley" on which a paraplegic patient, lying prone, is able to propel himself up and about. On this trolley the patient is, thereby, strengthening his arms and back extensors.

(vi) A "three-section bed" makes it possible to give patients who are in "back-lying" to carry out knee flexion and extension exercises without interfering with the hip joints, where this has to be avoided.

(vii) It struck me that carcinoma is not strictly a disease of the old age. We have had young patients of between 18 and 25 years with malignant tumours of the spine, mouth and rectum.

(viii) Stevens-Johnson Syndrome: A disease characterised by haemoptysis, measles-like rash, pyrexia with bucal blebs, peeling of superficial layer of skin, looseness of the skin looking like first degree burns but without fluid exudation; superficial ulceration of skin-around eyes, mouth, penis, scrotum and scalp, tachycardia of approximately 120 , normal blood pressure. The patient is agitated, unable to open his mouth with teeth tightly clenched. The patient died about three days after admission.

(ix) I saw on X-rays that not all hearts are situated more on the left side; we had a patient whose heart was situated on the right side.

(x) Our patients can spend up to six hours in the physiotherapy department, arriving in the Centre in the morning, leaving for lunch and returning in the afternoon. The patients are treated and given time to rest and then treatment can be continued again. The system in this Centre is that no physiotherapist "owns" a patient. Patients are treated by all physiotherapists. With this system one patient can receive more than six treatments in a day from different physiotherapists with different treatment methods. We are allowed to apply any technique and treatment methods we have learned in our training, to which we add the special experiences of this department. I have found that my previous training has stood me in good stead and is respected by the other members of the staff.

\section{ACKNOWLEDGEMENTS}

I wish to express appreciation to Mr. A. Rothberg, our Superintendent Physiotherapist, for his help and advice in the preparation of this article. 